\title{
Arthroscopic Bankart and Remplissage for Anteroinferior Instability With Subcritical Bone Loss Has a Low Recurrence Rate
}

\author{
Shirish Pathak, M.S. ORTHO DNB ORTHO, Murtaza J. Haidermota, M.S. ORTHO, \\ Vimal Kumar K. H., Diploma Orthopaedics, DNB Orthopaedics, FNB Sports Medicine, and \\ Parag Sancheti, M.S. ORTHO DNB ORTHO MCH ORTHO
}

\begin{abstract}
Objective: To demonstrate whether arthroscopic remplissage can achieve good outcomes without significantly impairing shoulder function. Methods: Consecutive patients with recurrent anterior glenohumeral dislocation, glenoid bone loss $<20 \%$, and engaging Hill-Sachs lesion who were operated with arthroscopic Bankart repair and remplissage between 2013 and 2016 were identified. Patients were evaluated clinically for shoulder instability, range of motion, and scored as per Oxford Shoulder Instability Score and University of California at Los Angeles score. The data were analyzed with the paired $t$ test and the Wilcoxon signed rank test, as applicable. For all analyses, statistical significance was set at $P<.05$. Results: Twenty-four patients were included in the study. The average age of the patients was 30 years (range, $18-47$ years $)$, with $91.67 \%(\mathrm{n}=22)$ male patients and $8.33 \%(\mathrm{n}=2)$ female patients. The range of motion at follow-up was comparable with the normal side, with loss of external rotation of $3.33^{\circ}(\mathrm{n}=24)$. Significant improvement was observed in the Oxford Shoulder Instability Score $(21.95$ vs $41.29, P<0.001)$ and University of California at Los Angeles score (18.33 vs 30.29, $P<.001$ ). A failure rate of $4.17 \%$ (1 patient with a positive apprehension test) was seen. Conclusions: Arthroscopic Bankart repair with the remplissage procedure helps to re-establish stability and achieve good shoulder outcomes for patients with recurrent anterior glenohumeral dislocation and an engaging Hill-Sachs lesion and without significant glenoid bone loss. Level of Evidence: Level IV, therapeutic.
\end{abstract}

$\mathbf{T}$ he symptomatic abnormal motion of the humeral head relative to the glenoid during active shoulder motion is defined as shoulder instability. ${ }^{1}$ Recurrent instability can be caused by traumatic anterior glenohumeral dislocations or subluxations, especially in young contact athlete patients, more so if there is associated bone loss. ${ }^{2,3}$ Traumatic unidirectional anterior shoulder instability is widely treated by arthroscopic Bankart repair. However, when bony defects are not identified or addressed during surgery, several studies have shown an increased failure rate after

From the Department of Shoulder and Sports Medicine, Deenanath Mangeshkar Hospital and Research Centre (S.P., V.K.K.H.); and Department of Orthopaedics, Sancheti Institute for Orthopaedics and Rehabilitation, Shivajinagar, (M.J.H, P.S.), Maharashtra, India.

The authors report that they have no conflicts of interest in the authorship and publication of this article. Full ICMJE author disclosure forms are available for this article online, as supplementary material.

Received March 29, 2021; accepted December 16, 2021.

Address correspondence to Dr. Vimal Kumar K. H., DIPLOMA (ORTHO), DNB (ORTHO), FNB SPORTS MEDICINE (DMH, PUNE), Department of Shoulder and Sports Medicine, 1st Floor, SS Building, Deenanath Mangeshkar Hospital and Research Centre, Erandawane, Pune-411004, arthroscopic stabilization. ${ }^{4-7}$ For marked glenoid bone defects with anterior instability, Latarjet or other bonegrafting procedures are widely accepted. ${ }^{4,6,8,9}$

Humeral bone defects or Hill-Sachs lesions, since being described in $1940,{ }^{10}$ have been reported in subsequent studies to have a prevalence of up to $70 \%$ of initial dislocations ${ }^{11,12}$ and up to $90 \%$ in recurrent dislocations. ${ }^{11,13,14}$ Hill and Sachs, after reviewing existing literature at that time, came to the conclusions that these defects represented a compression fracture of the posterolateral aspect of the humeral head, also

Maharashtra, India.E-mail: khvimalkumar1987@gmail.com;Dr. Shirish Pathak, M.S. (ORTHO), DNB (ORTHO), F. ISAKOS, Department of Shoulder and Sports Medicine, 1st Floor, SS Building, Deenanath Mangeshkar Hospital and Research Centre, Erandawane, Pune-411004, Maharashtra, India. E-mail:drshirishp@gmail.com

(C) 2022 THE AUTHORS. Published by Elsevier Inc. on behalf of the Arthroscopy Association of North America. This is an open access article under the CC BY-NC-ND license (http://creativecommons.org/licenses/by-nc-nd/4.0/). 2666-061X/21400

https://doi.org/10.1016/j.asmr.2021.12.014 
known as Hill-Sachs lesion, that they were commonly found in such cases of anterior glenohumeral dislocation, and that they often occurred at the time of the initial dislocation itself. ${ }^{15}$ If the Hill-Sachs lesion stays on the glenoid track, it is known as on-track lesion, and there is no risk of engagement. If the Hill-Sachs lesion is out of the glenoid track, it is known as off-track lesion, and there is a risk of engagement and dislocation. ${ }^{16}$ Burkhart and De Beer defined the concept of engaging Hill-Sachs, ${ }^{6,17}$ whereby "engagement" of the Hill-Sachs lesion on the anterior rim of the glenoid occurred with the shoulder in 90 of abduction and more than 30 of external rotation. ${ }^{17}$ These defects can be treated by various proposed techniques. ${ }^{18-20}$ Among these techniques, the remplissage procedure has been accepted as a dependable method to treat humeral bone loss and the risks of recurrent glenohumeral instability associated with it, especially in the presence of moderate $(<20 \%)$ glenoid bone loss. ${ }^{17,21-24}$ French for "to fill in," the remplissage procedure, described by Wolf and Pollack, ${ }^{25}$ involves advancement of the infraspinatus tendon and the posterior capsule into the Hill-Sachs defect, with the help of suture anchors. A modification of this technique to tie the sutures over the infraspinatus tendon rather than over the muscle, was described by Koo et al. ${ }^{26}$ The aims of the remplissage technique are to prevent anterior translation of the humeral head by making the infraspinatus tenodesis acting as a checkrein and to convert the intra-articular pathology into an extra-articular one. ${ }^{22}$ The outcome studies of remplissage have demonstrated fine results with high outcome scores and low recurrence rates. ${ }^{11,17,21-24}$ The main cited drawback of remplissage is the decrease in external rotation due to the infraspinatus tendon being tethered in a nonanatomic location. ${ }^{11,22,27-29}$ Pain, mainly in the posterosuperior region of the shoulder, is also a potential drawback of the remplissage procedure. ${ }^{24,30-32}$ The purpose of our study is to demonstrate whether arthroscopic remplissage can achieve good outcomes without significantly impairing shoulder function.

Our hypothesis is that arthroscopic remplissage procedure along with Bankart repair for the treatment of anterior glenohumeral instability with engaging large Hill-Sachs lesion without significant glenoid bone loss is associated with good functional outcomes with no significant notable loss of shoulder range of motion and low rates of recurrent glenohumeral instability, and postoperative complications.

\section{Methods}

We performed a retrospective follow-up of patients who underwent the remplissage procedure along with Bankart repair, from 2013 to 2016. The inclusion criteria were age older than 18 years, patients with diagnosed recurrent traumatic anterior instability, presence of glenoid bone loss $<20 \%$, such that a Bankart repair was indicated as opposed to a bone graft procedure, presence of humeral bone loss between $20 \%$ and $40 \%$ of humeral head circumference as determined by preoperative magnetic resonance imaging (MRI) and computed tomography (CT), presence of an engaging Hill-Sachs lesion on intraoperative dynamic evaluation, and postoperative follow-up of minimum of 2 years.

Exclusion criteria used were the presence of anterior glenoid rim fracture or glenoid bone defect $>20 \%$ of the inferior glenoid diameter such that a bone grafting procedure is indicated, epilepsy, revision surgery after failure of initial surgery.

\section{Preoperative Evaluation}

A detailed history was elicited from all the patients regarding etiology of shoulder instability, mode of injury, the hand dominance of the patient, involvement in any sporting activities, the number of previous dislocations, and ease with which reduction of the shoulder joint was carried out. Clinical examination of the patient with respect to shoulder range of movement and special tests for anterior glenohumeral instability. An apprehension test, Jobe's relocation test, and anterior drawer test were carried out. Oxford Shoulder Instability Score, University of California at Los Angeles (UCLA) score, and Beighton's scoring system for hyperlaxity were calculated. Radiographs of the involved shoulder in anteroposterior and axillary lateral views (Fig 1) were done. Imaging in the form of MRI (Fig 2) and CT scans (Fig 3) were done. The preoperative 3-dimensional CT scans were used to determine Hill-Sachs defect width and depth (Fig 3A) and the percentage of the glenoid bone loss (Fig 3B) by using the method described by Sugaya et al. ${ }^{33}$ on the en face view. All patients were assessed by author (S.P.) and coauthor (H.M.).

\section{Surgical Procedure and Intraoperative Evaluation}

All the surgeries were done under the cover of a combination of hypotensive general anesthesia and interscalene block. All the patients were positioned in the lateral decubitus position with longitudinal and vertical 2-pulley traction system (Fig 4). Evaluation under anesthesia was done and the anterior shoulder instability was confirmed. The glenohumeral joint was entered through a primary posterior portal, such that it was directly over the Hill-Sachs defect for the purpose of viewing and anchor placement. The anterosuperior portal (Fig 5), primarily used for visualization of the Bankart tear and Hill-Sachs defect (Fig 5) while working from the posterior portal, was placed slightly posterior than normal, through the cuff. The presence of an engaging off-track Hill-Sachs defect (Fig 5) was dynamically evaluated. An anteroinferior portal also 
Fig 1. Preoperative radiograph of the right shoulder showing true anteroposterior (AP) and axillary lateral views.

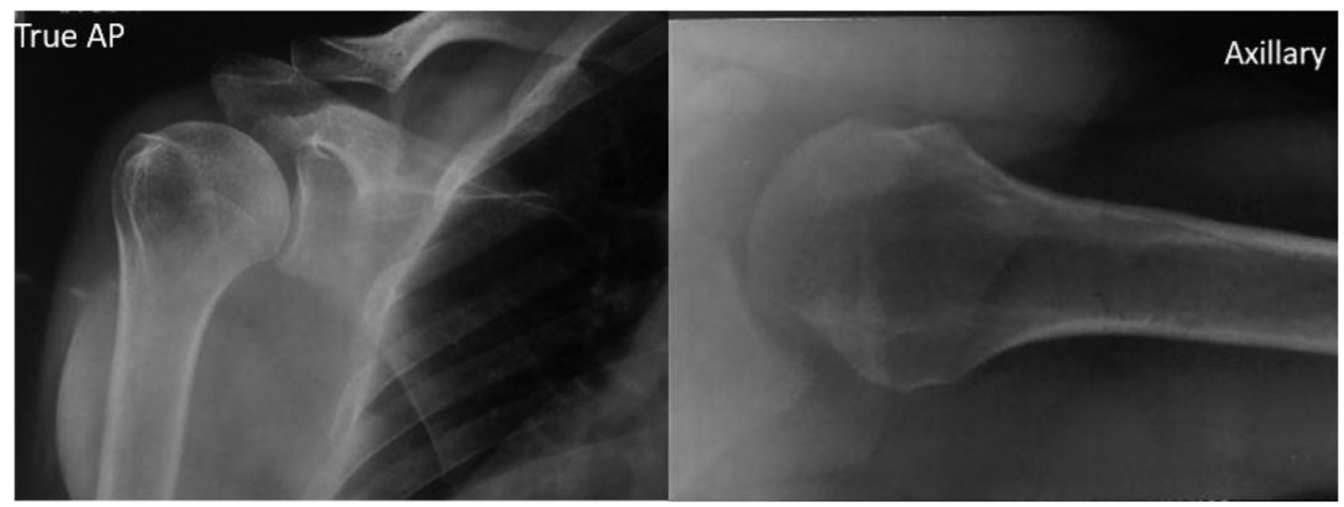

was established, primarily as a working portal for the Bankart repair. The glenoid was prepared, and the anteroinferior glenoid labrum was mobilized to the glenoid margin. Then, 3-4 single-loaded 2.3-mm suture anchors (PEEK, BIORAPTOR; Smith 8 Nephew, Andover, MA) were used to oppose the anteroinferior labrum to the glenoid and sutures were passed but knotting was not done at this point. Debridement of the Hill-Sachs defect and preparation of a bed for placement of an anchor was done. Through the posterior portal, a $5.5 \mathrm{~mm}$ triple loaded cuff anchor (Peek corkscrew FT, Triple Play; Arthrex, Naples, FL) was inserted in the center of the Hill-Sachs defect (Fig 6) (central point of the defect in the mediolateral direction slightly more toward articular surface of humerus as well as superoinferior direction). The cannula $(8-\mathrm{mm}$ plastic transparent cannula DRI-LOK disposable cannula, 8 $\mathrm{mm} * 75 \mathrm{~mm}$, threaded, red; Stryker, San Jose, CA) was withdrawn external to the infraspinatus (Fig 7A) and a penetrating bird-beak suture passer (Tissue Penetrator; Arthrex) (Fig 7B) was used to pass 3 mattress sutures through the infraspinatus tendon and the posterior capsule (Fig 7C). Again, the knotting of these sutures was not done at this point. Using the anteroinferior portal, the sutures of the Bankart repair were knotted using a knot-pusher (DePuy Mitek, Raynham, MA), such that the avulsed part of the anteroinferior glenoid labrum was well opposed and firmly attached to the glenoid margin (Fig 8A). Using the posterior portal, the remplissage sutures were knotted. The stability of the Bankart repair and remplissage procedure was checked with dynamic movements of the shoulder after the remplissage procedure (Fig 8B) was completed.

\section{Postoperative Rehabilitation}

The operated shoulder was immobilized for 3 weeks postoperatively in an arm pouch. During the initial 3 weeks, hand grip, elbow, and neutral rotation exercises were allowed, followed by pendulum exercise and isometric cuff strengthening during the third to sixth week. After 6 weeks, range of motion exercises were started and at 12 weeks strengthening and proprioception exercises were begun. Sports-specific training and contact-sports were started once the patient had gained full range of motion and stability, usually at about 8 to 9 months after surgery.
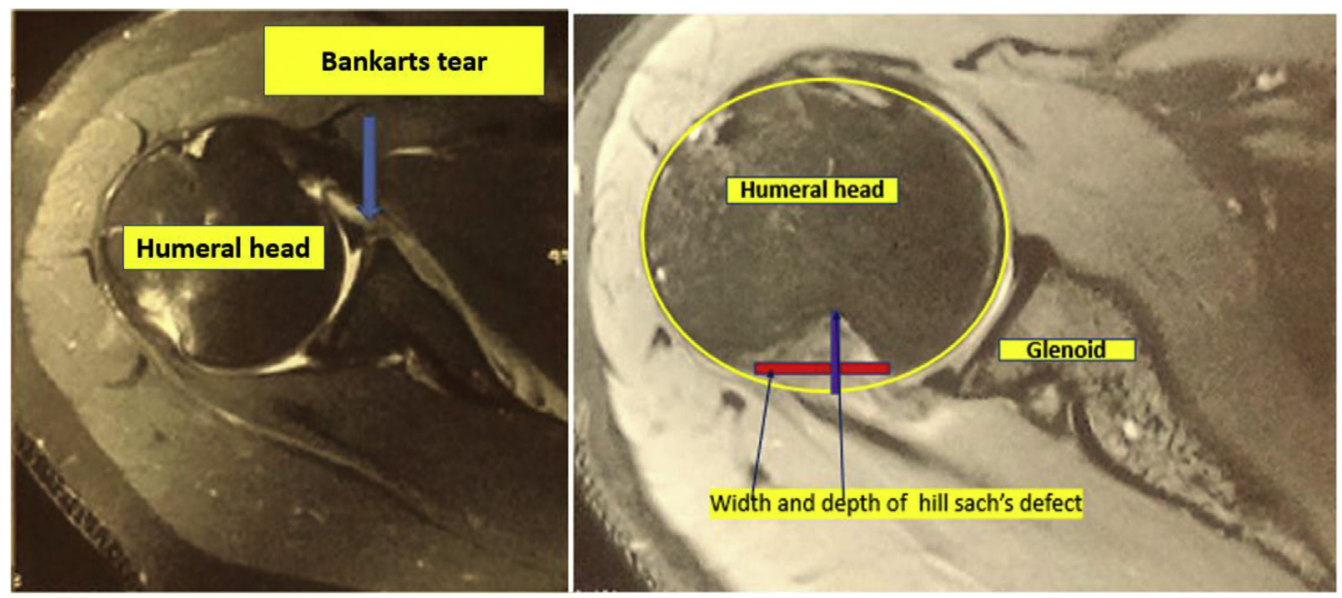

Fig 2. Preoperative Tl-weighted magnetic resonance (axial) image of the right shoulder showing the Bankart tear and Hill-Sachs lesion. 


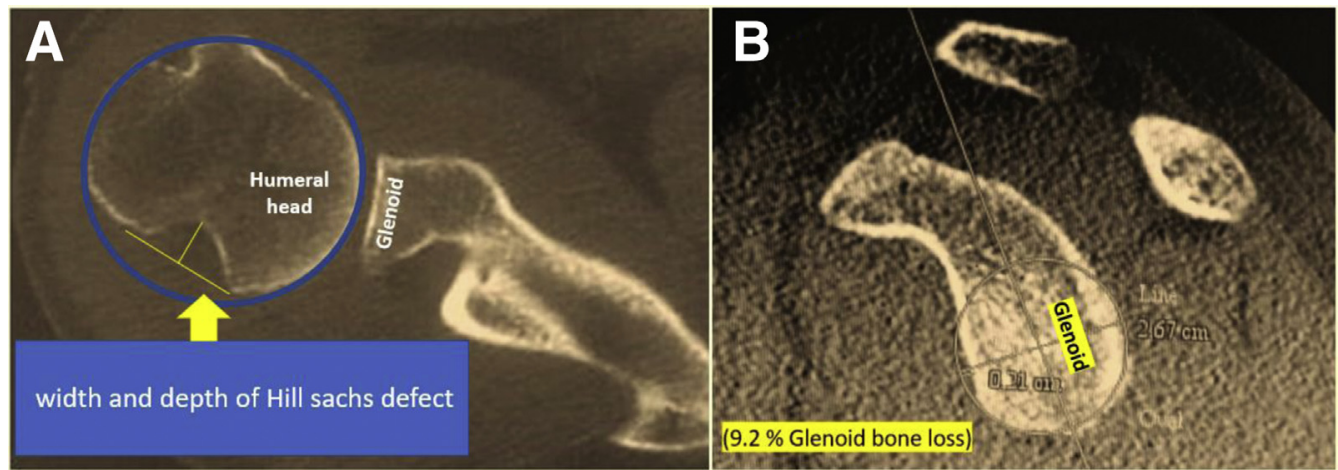

Fig 3. Preoperative computed tomography scan of the right shoulder. (A) Axial image showing the Hill-Sachs lesion. (B) Sagittal image showing glenoid bone loss.

\section{Follow-up Postoperatively}

The operated patients were called for follow-up after 3 weeks, 12 weeks, 6 months, 1 year, and yearly thereafter. At each follow-up, the stability, mobility and strength of the shoulder joint was assessed clinically by the apprehension test, Jobe's relocation test, and the anterior drawer test. Functional scoring was done using the Oxford Shoulder Instability Score and the UCLA score, by the same independent surgeon (S.P.) who evaluated the patients preoperatively. External and internal rotation was assessed with the arm $\left(90^{\circ}\right.$ abduction) and with the elbow flexed at $90^{\circ}$. Failure of the treatment was defined as any redislocation, subluxation, or positive apprehension test at follow-up.

\section{Statistical Analysis}

Associations between patient characteristics (age, sex, handedness, side of surgery) and patient outcome measures pre- and postoperatively (range of motion, apprehension test, Jobe's relocation test, anterior drawer test, Oxford Shoulder Instability Score, UCLA score, number of postoperative dislocations) were examined. Statistical analysis was performed using the paired $t$ test and the Wilcoxon signed rank test, as applicable. For all analyses, statistical significance was deemed present if $P<.05$.

\section{Results}

\section{Demographic Characteristics}

Out of the 30 patients who met our inclusion criteria and were included initially in our study, 6 patients $(20 \%)$ were lost to follow-up, leaving 24 patients (and 24 shoulders) available at follow-up. All patients underwent primary surgery $(100 \%)$, and there were no revision surgeries in our study. The average duration of follow-up in our study was 33 months (range, 24-41 months). The average age of the patients at surgery was 30 years (range, 18-47 years). There were $22(91.67 \%)$ male patients in our study and $2(8.33 \%)$ female patients. The left shoulder was operated upon in 11 $(45.83 \%)$ patients and the right in $13(54.17 \%)$

Fig 4. Patient in the left lateral position with operative right shoulder in $20^{\circ}$ forward flexion and $60^{\circ}$ abduction showing traction and countertraction system used for Bankart and remplissage repair.

Longitudinal and vertical 2 pulley Double arm traction system

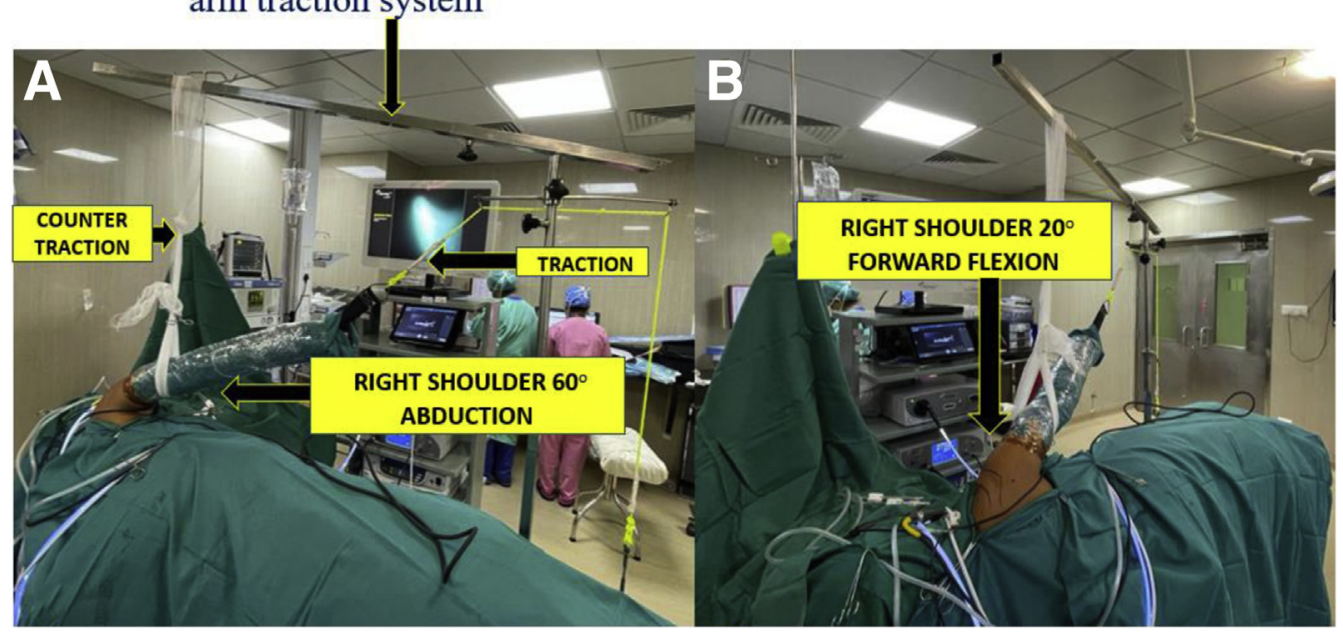




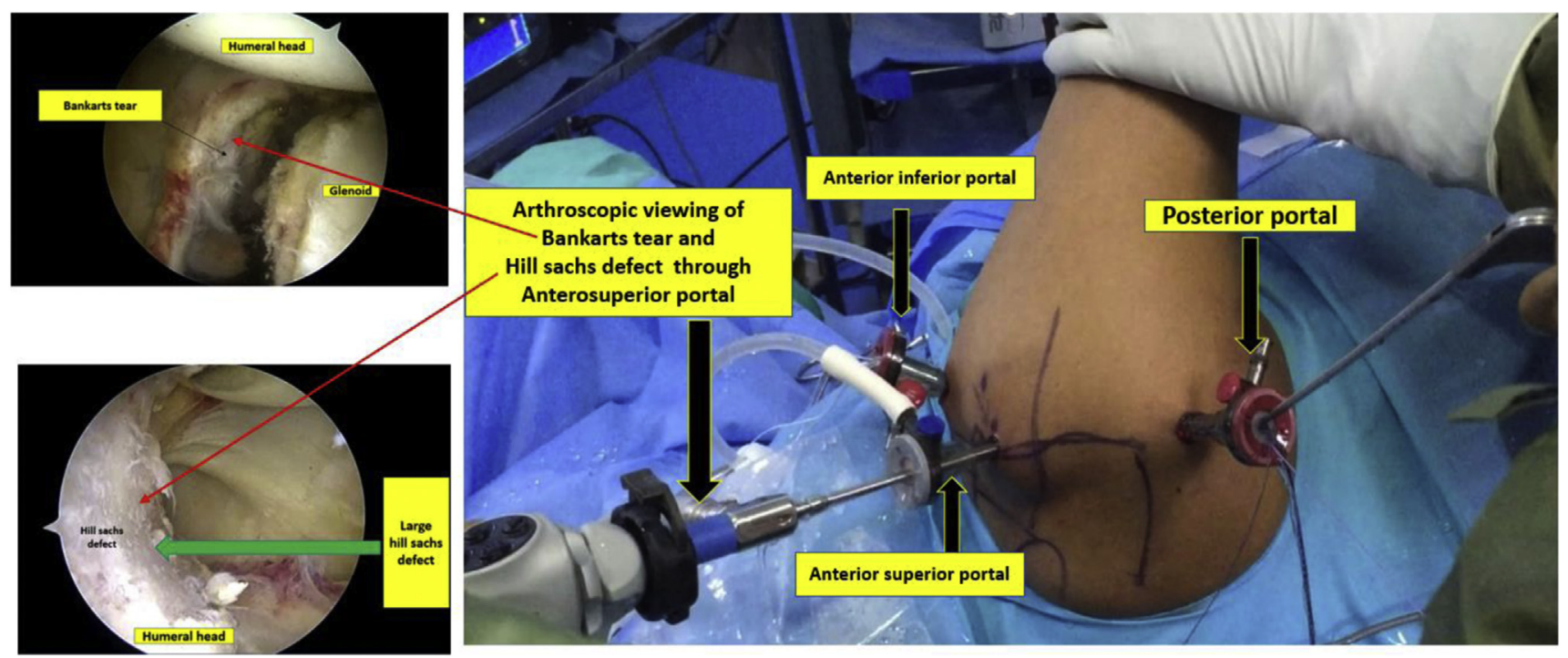

Fig 5. Patient in the left lateral position with right shoulder in $20^{\circ}$ forward flexion and $60^{\circ}$ abduction. Arthroscopic viewing of Bankart tear and Hill-Sachs defect through anterosuperior portal.

patients. In total, $75 \%(\mathrm{n}=18)$ of the patients underwent surgery on the dominant extremity, whereas in $25 \%(n=6)$ the opposite, non-dominant shoulder was operated upon.

\section{Preoperative Examination and Scoring}

For comparing preoperative and postoperative range of movement of affected shoulder, preoperative range of movements of unaffected shoulder was taken as patients had pain and apprehension in the affected shoulder. The average active forward flexion and extension of the unaffected normal shoulder were $178.33^{\circ}\left( \pm 4.81^{\circ}\right)$ and $66.25^{\circ}\left( \pm 5.76^{\circ}\right)$, respectively. Average abduction was $177.08^{\circ}\left( \pm 5.50^{\circ}\right)$. The average internal and external rotations in $90^{\circ}$ abduction of the normal shoulder were $77.5^{\circ}\left( \pm 4.23^{\circ}\right)$ and $74.58^{\circ}$ $\left( \pm 7.21^{\circ}\right)$. Positive apprehension, Jobe's relocation, and anterior drawer tests were present in all 24 patients $(100 \%)$ preoperatively. Average glenoid bone loss was $7.55 \%( \pm 3.34 \%)$. Average Hill-Sachs lesion was $23.79 \%( \pm 5.54 \%)$ by head circumference method. Average width of Hill-Sachs lesion was $20.29 \mathrm{~mm}$ $( \pm 3.61 \mathrm{~mm})$ and average depth of Hill-Sachs lesion was $7.41 \mathrm{~mm}( \pm 1.5 \mathrm{~mm})$. The average Oxford shoulder instability score for the involved shoulder preoperatively was $21.95( \pm 3.09)$ with range 17 to 30 . The average UCLA score was $18.33( \pm 3.60)$, ranging from 14 to 24 (Table 1). The Beighton scoring system was negative for hyperlaxity i.e., $\leq 3$ in all 24 patients $(100 \%)$.

\section{Intraoperative Findings}

All 24 patients $(100 \%)$ had a Bankart tear (anteroinferior glenoid labrum tear) with associated glenoid bone loss covering $<20 \%$ of the width of the glenoid. A Hill-Sachs lesion causing humeral head bone loss between $20 \%$ and $40 \%$ was present in all the 24 patients $(100 \%)$. All cases $(n=24)$ had an engaging large Hill-Sachs lesion which was determined on dynamic evaluation intraoperatively. No rotator cuff tears were present in any of the patients, but 1 patient $(4.17 \%)$ had an associated SLAP tear, which was repaired at the same time.

\section{Postoperative Examination and Scoring}

At follow-up, the average active forward flexion and extension of the operated shoulder were $177.08^{\circ}$ $\left( \pm 5.50^{\circ}\right)$ and $65.41^{\circ}\left( \pm 7.79^{\circ}\right)$, respectively. Average abduction was $175^{\circ}\left( \pm 8.34^{\circ}\right)$. The average internal and external rotations in $90^{\circ}$ abduction of the operated shoulder were $75.83^{\circ}\left( \pm 6.53^{\circ}\right)$ and $71.25^{\circ}\left( \pm 9.91^{\circ}\right)$, of which $75 \%(\mathrm{n}=18)$ did not have reduction in external

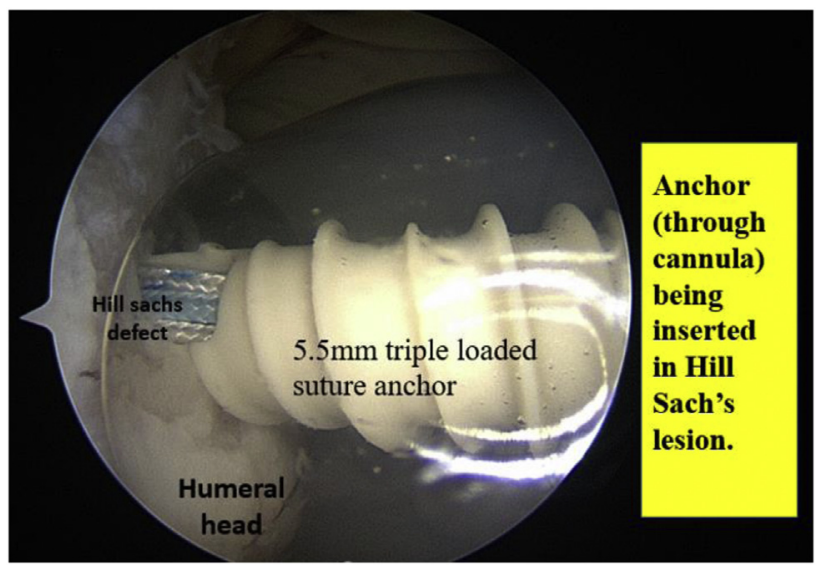

Fig 6. Patient in the left lateral position with right shoulder in $20^{\circ}$ forward flexion and $60^{\circ}$ abduction. Arthroscopic viewing through the anterosuperior portal showing anchor being inserted in Hill-Sachs lesion. 
A

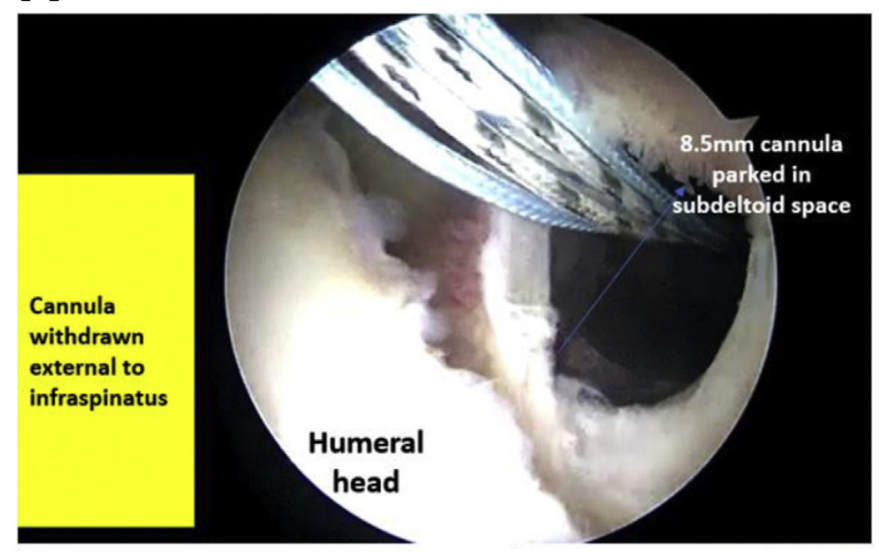

B

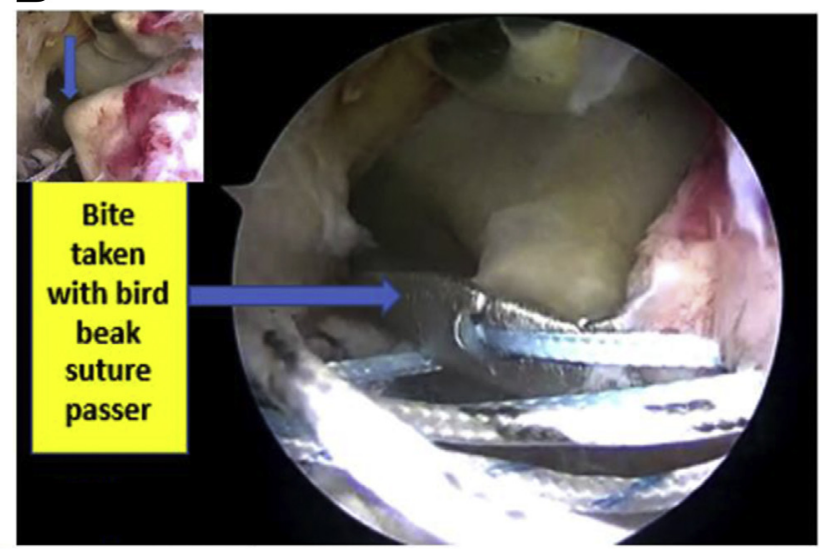

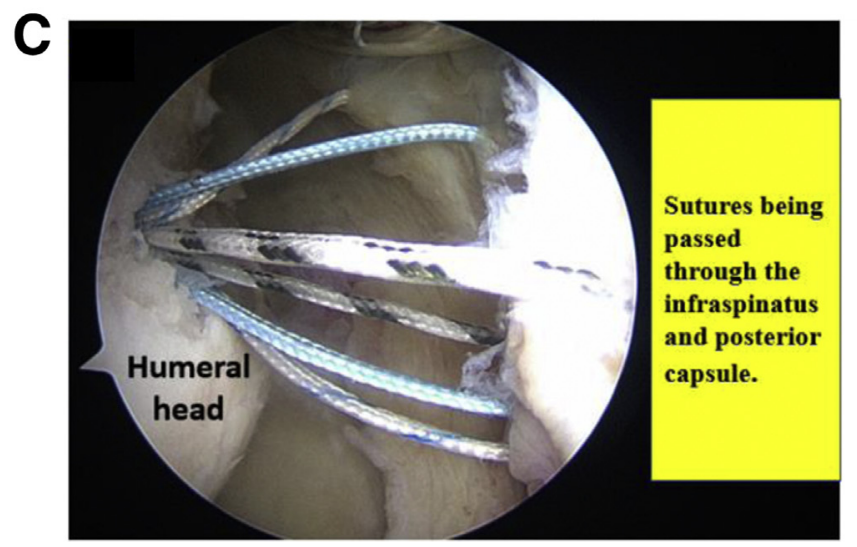

Fig 7. Patient in the left lateral position with right shoulder in $20^{\circ}$ forward flexion and $60^{\circ}$ abduction. Arthroscopic viewing through Anterosuperior portal. (A) Cannula withdrawn external to infraspinatus. (B) Bite taken with direct suture passer. (C) Sutures being passed through infraspinatus and posterior capsule.

rotation but $25 \%(\mathrm{n}=6)$ had reduced external rotation compared with opposite normal shoulder. This loss of range of external rotation was from 0 to $20^{\circ}$ and on an average, the patients lost $3.33^{\circ}(\mathrm{n}=24)$ of external rotation (Table 1 ). Other loss of movements were $1.25^{\circ}$ of forward flexion $(P=.43), 0.83^{\circ}$ of extension $(P=$ $.41), 2.08^{\circ}$ of abduction $(P=.16)$, and $1.67^{\circ}$ of internal rotation $(P=.10)$. One patient $(4.17 \%)$ on follow-up had positive apprehension, Jobe's relocation, and anterior drawer tests, whereas it was negative in 23
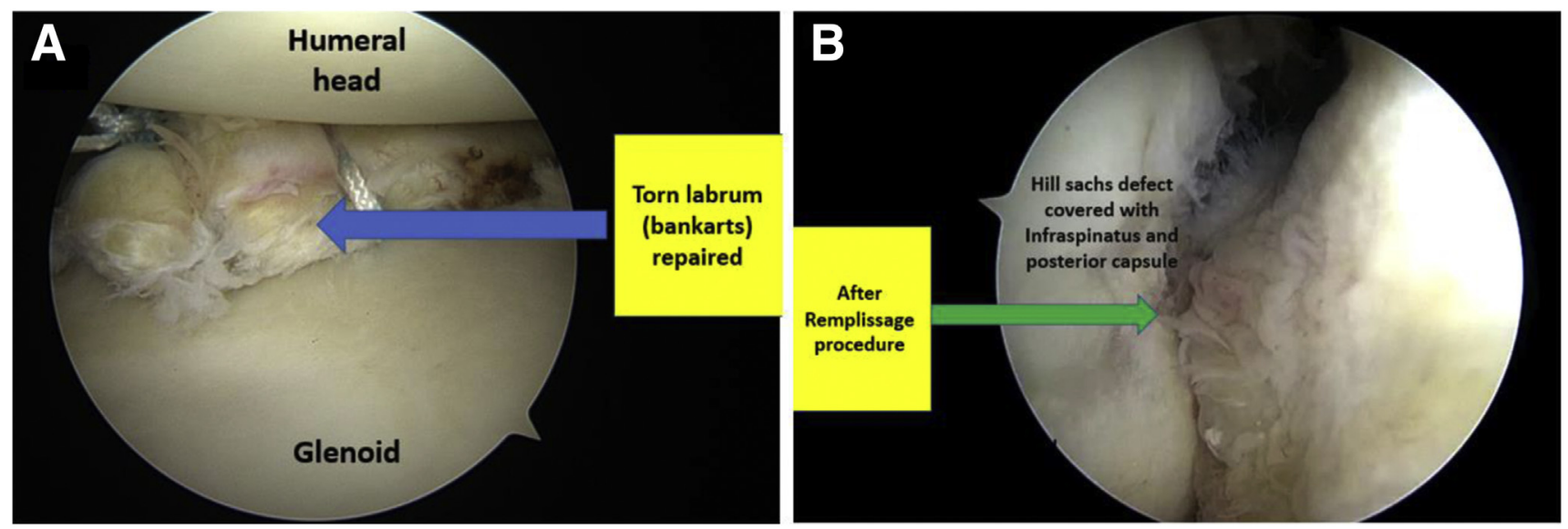

Fig 8. Patient in the left lateral position with right shoulder in $20^{\circ}$ forward flexion and $60^{\circ}$ abduction. (A) Arthroscopic viewing through the posterior portal showing repaired Bankart tear. (B) Arthroscopic viewing through the anterosuperior portal after completion of remplissage procedure. 
Table 1. Patient's Preoperative and Postoperative Range of Motion and Functional Scores

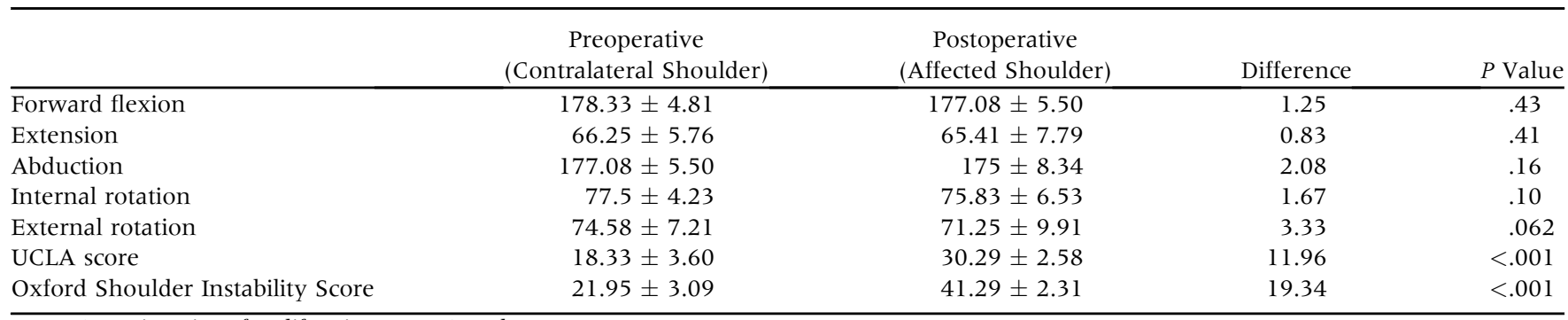

UCLA, University of California at Los Angeles.

patients $(95.83 \%)$. The average Oxford Shoulder Instability Score for the involved shoulder increased from $21.95 \pm 3.09$ preoperatively to $41.29 \pm 2.31(P<$ $.001)$ postoperatively. The average UCLA score increased from $18.33 \pm 3.60$ preoperatively to $30.29 \pm$ $2.58(P<.001)$ postoperatively, thereby depicting statistically significant $(P<.01)$ improvement in both Oxford shoulder instability and UCLA scores at followup (Table 1).

Two patients $(8.33 \%)$ on follow-up complained of posterosuperior pain of the operated shoulder. No patient in our study experienced a redislocation or subluxation postoperatively. However, 1 patient $(4.17 \%)$ had a positive apprehension test at follow-up and was dissatisfied with the procedure. Therefore, the overall failure rate of our study is $4.17 \%$ ( 1 of 24$)$.

\section{Discussion}

In our study of patients who underwent surgery, the average UCLA score increased from $18.33 \pm 3.60$ preoperatively to $30.29 \pm 2.58(P<.001)$ postoperatively, which is similar to findings in other previous studies. $^{27,34,35}$ The average Oxford Shoulder Instability Score for the involved shoulder increased from $21.95 \pm$ 3.09 preoperatively to $41.29 \pm 2.31(P<.001)$ postoperatively, which is comparable to a similar undertaken study by Brilakis et al. ${ }^{36}$

In our study $25 \%(\mathrm{n}=6)$ had reduced external rotation postoperatively. This loss of range of external rotation was from 0 to $20^{\circ}$ and, on an average, the patients lost $3.33^{\circ}(\mathrm{n}=24)$ of external rotation postoperatively compared with preoperative external rotation of normal shoulder. The overall failure rate of this study was $4.17 \%$ (0 redislocations, 0 subluxations, and 1 positive apprehension test of 24 patients).

A high failure rate after arthroscopic Bankart repair is found in patients with prominent bone defect on either the glenoid or the humerus. ${ }^{5-7,17}$ The extent of the contribution of an engaging humeral Hill-Sachs lesion to recurrent instability was studied by Burkhart and De Beer $^{6}$ in 2000. The involvement of a large, engaging Hill-Sachs lesion in recurrent glenohumeral instability has since been widely studied and acknowledged. ${ }^{20,22}$
Large humeral Hill-Sachs defects were treated by an open transfer of the infraspinatus tendon into large Hill-Sachs lesions in 1972, by Connolly. In 2004, at the annual meeting of the Arthroscopy Association of North America, Wolf and Pollack ${ }^{25}$ put forth their technique, "Arthroscopic Hill-Sachs remplissage," which was an arthroscopic transfer of infraspinatus tendon into the Hill-Sachs lesion. It was further published and popularized by Purchase et al. in 2008. The outcome studies on remplissage procedure have demonstrated fine results with improved high outcome scores, high patient satisfaction rates, and diminished recurrence and complication rates. ${ }^{17,21,22,24}$

There was no significant loss of shoulder movement at follow-up, which is comparable with similar studies. $^{21-24,34}$ Theoretical loss of external rotation after surgery is cited as one of the main drawbacks of the remplissage procedure. ${ }^{22,27-29}$ A statistically significant loss of external rotation was described by Deutsch and $\mathrm{Kroll}^{37}$ in their study. In our study postoperatively $25 \%$ $(n=6)$ had reduced external rotation. This loss of range of external rotation was from 0 to $20^{\circ}$ and, on average, the patients lost $3.33^{\circ}(\mathrm{n}=24)$ of external rotation postoperatively compared with preoperative external rotation of normal shoulder. This loss of external rotation $\left(3.33^{\circ}\right)$ that we observed in our study is well within the range quoted by other studies of $2^{\circ}$ to $9^{\circ}$, all of which did not find a significant difference. ${ }^{11,17,36}$ Loss of external rotation also depends on surgical technique, and the authors feel that this is partly because we captured only 1 to $1.5 \mathrm{~cm}$ of infraspinatus tendon (just lateral to musculotendinous junction of infraspinatus) while doing remplissage procedure. Thus, the remplissage procedure does not cause any clinically significant loss of external rotation, although some studies continue to express contrasting reports. ${ }^{28,38}$ Pain in the posterosuperior region of the shoulder was experienced by 2 patients $(8.33 \%)$ postoperatively, which is in accordance with certain studies. ${ }^{31,32}$ This posterosuperior pain was felt more during forceful movements of the shoulder or when tired.

The overall failure rate of this study was $4.17 \%(0$ redislocations, 0 subluxations, and 1 positive 
apprehension test, of 24 patients). Failure of the treatment was defined as any redislocation, subluxation, or positive apprehension test at follow-up. This failure rate of $4.17 \%$ is comparable with other studies, where the range of failure reported is $2 \%$ to $15 \%{ }^{17,21,24,39}$

Our hypothesis therefore holds true, as arthroscopic remplissage procedure along with Bankart repair for the treatment of anterior glenohumeral instability with engaging Hill-Sachs lesion, is associated with good postoperative functional shoulder outcomes, low failure, complication rate, no notable loss of shoulder range of motion.

\section{Limitations}

Our study, however, is not without its limitations. First, there is an inherent set of limitations associated with the retrospective nature of the study, one being recall bias. Also, a larger sample size and a longer follow-up period would have given us a larger and clearer picture about the outcome of the remplissage procedure. There is a lack of a control group comprising patients operated with isolated Bankart repair. Also, no postoperative MRI was done for the patients to document healing of the Bankart repair and the infraspinatus tendon within the Hill-Sachs lesion.

\section{Conclusions}

Arthroscopic Bankart repair with the remplissage procedure helps to re-establish stability and achieve good shoulder outcomes for patients with recurrent anterior glenohumeral dislocation and an engaging Hill-Sachs lesion and without significant glenoid bone loss.

\section{References}

1. De Filippo M, Schirò S, Sarohia D, et al. Imaging of shoulder instability. Skelet Radiol 2020;49:1505-1523.

2. Moya D, Aydin N, Yamamoto N, et al. Current concepts in anterior glenohumeral instability: diagnosis and treatment. SICOT J 2021;7:48.

3. Zacharia B, Prakas A, Vaidyanathan S, Roy A, Komalam Ayyub M. The shoulder instability: An overview. Int J Recent Surg Med Sci 2021;7:47-53.

4. Camus D, Domos P, Berard E, Toulemonde J, Mansat P, Bonnevialle N. Isolated arthroscopic Bankart repair vs. Bankart repair with "remplissage" for anterior shoulder instability with engaging Hill-Sachs lesion: A metaanalysis. Orthop Traumatol Surg Res 2018;104:803-809.

5. Dekker TJ, Peebles LA, Bernhardson AS, et al. Risk factors for recurrence after arthroscopic instability repair-the importance of glenoid bone loss $>15 \%$, patient age, and duration of symptoms: A matched cohort analysis. Am J Sports Med 2020;48:3036-3041.

6. Park I, Oh MJ, Shin SJ. Effects of glenoid and humeral bone defects on recurrent anterior instability of the shoulder. Clin Orthop Surg 2020;12:145-150.

7. Delgrande D, Lonjon G, Hardy P, et al. Long-term results of arthroscopic Bankart repairs for anterior instability of the shoulder in patients aged thirty years or older. Int Orthop 2021;45:1583-1589.

8. Hurley ET, Montgomery C, Jamal MS, et al. Return to play after the Latarjet procedure for anterior shoulder instability: A systematic review. Am J Sports Med 2019;47: 3002-3008.

9. White AE, Patel NK, Hadley CJ, Dodson CC. An algorithmic approach to the management of shoulder instability. J Am Acad Orthop Surg Glob Res Rev 2019;3. e19.00168.

10. Rosa JRP, Checchia CS, Miyazaki AN. Traumatic anterior instability of the shoulder. Rev Bras Ortop 2017;52: 513-520.

11. Parmar R, Kapoor S, Sharma B. Arthroscopic Bankart repair following traumatic recurrent shoulder dislocation: A prospective review of 30 cases. J Orthop Surg 2019;27: 2309499019832708.

12. Wang SI. Management of the first-time traumatic anterior shoulder dislocation. Clin Shoulder Elb 2018;21:169-175.

13. Matev B, Slavchev S. Shoulder instability-A frequent pathology-various methods of treatment. J IMAB 2019;25:2349-2354.

14. Gouveia K, Abidi SK, Shamshoon S, et al. Arthroscopic Bankart repair with remplissage in comparison to bone block augmentation for anterior shoulder instability with bipolar bone loss: A systematic review. Arthroscopy 2021;37:706-717.

15. Reider B. Conquering the Hill-Sachs. Am J Sports Med 2016;44:2767-2770.

16. Itoi E. 'On-track' and 'off-track' shoulder lesions. EFORT Open Rev 2017;2:343-351.

17. Ravikanth R, David M, Sandeep S, Abraham MJ. Prevalence of concomitant injuries with Hill-Sachs lesion in traumatic shoulder dislocations. J Orthop Allied Sci 2017;5: 58-62.

18. Yang JS, Mehran N, Mazzocca AD, Pearl ML, Chen VW, Arciero RA. Remplissage versus modified Latarjet for offtrack Hill-Sachs lesions with subcritical glenoid bone loss. Am J Sports Med 2018;46:1885-1891.

19. França FO, Godinho AC, Carneiro Leal DPC, et al. Clinical and image outcomes of the Hill-Sachs injury approach by the remplissage technique on the anterior shoulder instability. Rev Bras Ortop (Sao Paulo) 2019;54:13-19.

20. Zhuo H, Xu Y, Zhu F, Pan L, Li J. Osteochondral allograft transplantation for large Hill-Sachs lesions: A retrospective case series with a minimum 2-year follow-up. J Orthop Surg Res 2019;14:344.

21. Kakazu R, LeVasseur MR, Arciero RA, et al. State of the art for treatment of bony defects around anterior shoulder instability - the American perspective. Obere Extremitat 2021;16:16-21.

22. Trellopoulos A, Brilakis E, Antonogiannakis E. Alternative and additive arthroscopic soft-tissue procedures for anterior shoulder instability. Obere Extremitat 2021;16:8-15.

23. Bastard C, Herisson O, Gaillard J, Nourissat G. Impact of remplissage on global shoulder outcome: A long-term comparative study. Arthroscopy 2019;35:1362-1367.

24. Ko SH, Cha JR, Lee CC, Hwang IY, Choe CG, Kim MS. The influence of arthroscopic remplissage for engaging Hill-Sachs lesions combined with Bankart repair on redislocation and shoulder function compared with Bankart repair alone. Clin Orthop Surg 2016;8:428-436. 
25. Wolf EM, Pollack ME. Hill-Sachs "remplissage": An arthroscopic solution for the engaging Hill-Sachs lesion (SS-32). J Arthrosc Relat Surg 2004;20:el4-e15.

26. Koo SS, Burkhart SS, Ochoa E. Arthroscopic doublepulley remplissage technique for engaging Hill-Sachs lesions in anterior shoulder instability repairs. J Arthrosc Relat Surg 2009;25:1343-1348.

27. Hurley ET, Toale JP, Davey MS, et al. Remplissage for anterior shoulder instability with Hill-Sachs lesions: A systematic review and meta-analysis. J Shoulder Elbow Surg 2020;29:2487-2494.

28. Rahu M, Kartus JT, Põldoja E, Kolts I, Kask K. Hill-Sachs remplissage procedure based on posterosuperior capsulomuscular anatomy. Arthrosc Tech 2019;8:623-627.

29. Hatta T, Yamamoto N, Shinagawa K, Kawakami J, Itoi E. Surgical decision making based on the on-track/off-track concept for anterior shoulder instability: A case-control study. JSES Open Access 2019;3:25-28.

30. Garcia GH, Degen RM, Liu JN, Kahlenberg CA, Hurwit DJ, Dines JS. The "safe zone" technique improves suture placement and accuracy during arthroscopic remplissage: A cadaveric validation of a novel technique. J Arthrosc Rel Surg 2017;33:2-3.

31. Miyamoto R, Yamamoto A, Shitara H, et al. Clinical outcome of arthroscopic remplissage as augmentation during arthroscopic Bankart repair for recurrent anterior shoulder instability. Open Orthop J 2017;11:1268-1276.

32. Idowu O, Chiu M, Miller J, Koh J, Shi L. Remplissage-when and how to fill in the defect. Ann Joint 2017;2:61.

33. Sugaya H, Moriishi J, Kanisawa I, Tsuchiya A. Arthroscopic osseous Bankart repair for chronic recurrent traumatic anterior glenohumeral instability. J Bone Joint Surg Am 2005;87:1752-1760.

34. Liu JN, Gowd AK, Garcia GH, Cvetanovich GL, Cabarcas BC, Verma NN. Recurrence rate of instability after remplissage for treatment of traumatic anterior shoulder instability: A systematic review in treatment of subcritical glenoid bone loss. Arthroscopy 2018;34: 2894-2907.

35. Domos P, Ascione F, Wallace AL. Arthroscopic Bankart repair with remplissage for non-engaging Hill-Sachs lesion in professional collision athletes. Shoulder Elbow 2019;11:17-25.

36. Brilakis E, Mataragas E, Deligeorgis A, Maniatis V, Antonogiannakis E. Midterm outcomes of arthroscopic remplissage for the management of recurrent anterior shoulder instability. Knee Surg Sports Traumatol Arthrosc 2016;24:593-600.

37. Deutsch AA, Kroll DG. Decreased range of motion following arthroscopic remplissage. Orthopedics 2008;31: 492.

38. Kamat N, Ajri A, Sodhai VM, Kalamb V, Shyam AK, Sancheti PK. Does addition of remplissage procedure cause external rotation deficit in the patient undergoing standard Bankart repair for recurrent shoulder dislocation with engaging Hill-Sach's lesions? Acta Shoulder Elbow Surg 2020;4:7-10.

39. Panzram B, Kentar Y, Maier M, Bruckner T, Hetto P, Zeifang F. Mid-term to long-term results of primary Arthroscopic Bankart repair for traumatic anterior shoulder instability: A retrospective study. BMC Мusculoskelet Disord 2020;21:191. 